\title{
Türkiye'de Gelir, Enerji Tüketimi, Ticari Açıklık ve Çevre Koruma Harcamaları: ÇKE Hipotezinin Bölgesel Analizi
}

\author{
Income, Energy Consumption, Trade Openness and Environmental \\ Protection Expenditures in Turkey: A Regional Analysis \\ of the EKC Hypothesis
}

Mürşit Recepoğlu ${ }^{1}$

EMPIRICAL

ARTICLE

\begin{tabular}{l} 
ARTICLE INFO \\
\hline Submitted : 23.10.2021 \\
Revised : 07.12 .2021 \\
Accepted : 09.12.2021 \\
Available : 25.12.2021 \\
\hline iThenticate similarity \\
score: 13\% \\
\hline JEL classification: \\
O44, O53, Q58 \\
\hline Keywords: \\
Environmental Kuznets \\
Curve, Government \\
Expenditures, \\
Economic Growth, \\
Regional Development, \\
Dynamic Panel Data \\
Analysis
\end{tabular}

\section{ARTICLE INFO}

Submitted : 23.10 .2021

Accepted : 09.12.2021

Available : 25.12.2021

iThenticate similarity score: $13 \%$

JEL classifica

Keywords:

Environmental Kuznets

Curve, Government

Dynamic Panel Data

Analysis

\begin{abstract}
A B S T R A C T
Environmental pollution is an important threat for sustainable economic development at the national and the regional level. Nevertheless, regional studies investigating the determinants of the environmental pollution in Turkey are limited. This study analyzes the effects of income, energy consumption, trade openness and environmental protection expenditures on the environmental pollution in NUTS 2 regions of Turkey for the period 2007-2019 within the framework of the Environmental Kuznets Curve (EKC) hypothesis. The findings obtained from the study using the Two Step System Generalized Moments Method show that the EKC hypothesis is not valid in Turkey for NUTS 2 regions. Morever, energy consumption has a statistically significant and positive effect on the environmental pollution, while trade openness has a negative effect. However, environmental protection expenditures do not have statistically significant effects on the environmental pollution. These results reveal that the effectiveness of the economic and fiscal policies implemented at the regional level to increase the environmental quality should be increased.
\end{abstract}

Cite this article as: Recepoğlu, M. (2021). "Türkiye'de Gelir, Enerji Tüketimi, Ticari Açıklık ve Çevre Koruma Harcamaları: ÇKE Hipotezinin Bölgesel Analizi”, International Journal of Public Finance, 6(2), 353-372.

\footnotetext{
${ }^{1}$ Assist. Prof. PhD., Gümüşhane University, Department of Accounting and Taxation, Turkey, ORCID: 0000-0002-6861-2607, mursit_recepoglu@hotmail.com
} 
Recepoğlu, M. (2021). “Türkiye'de Gelir, Enerji Tüketimi, Ticari Açıklık ve Çevre Koruma Harcamaları: ÇKE Hipotezinin Bölgesel Analizi", International Journal of Public Finance, 6(2), 353-372.

\begin{tabular}{|c|c|}
\hline MAKALE BíLGISI & ÖZET \\
\hline Gönderme: 23.10 .2021 & Çevre kirliliği, ulusal ve bölgesel düzeyde sürdürülebilir ekonomik \\
\hline Düzeltme : 07.12.2021 & kalkınma için önemli bir tehdittir. Ancak, Türkiye'de çevre kirliliğinin \\
\hline Kabul $\quad: 09.12 .2021$ & belirleyicilerini araştıran bölgesel çalışmalar sınırlı düzeydedir. Bu çalışma \\
\hline Yayın $\quad: 25.12 .2021$ & Türkiye'nin Düzey 2 bölgelerinde gelir, enerji tüketimi, ticari açıklık ve \\
\hline $\begin{array}{l}\text { iThenticate benzerlik } \\
\text { oranı: } \% 13\end{array}$ & $\begin{array}{l}\text { çevre koruma harcamalarının çevre kirliliği üzerindeki etkilerini Çevresel } \\
\text { Kuznets Eğrisi (ÇKE) hipotezi çerçevesinde 2007-2019 dönemi için analiz }\end{array}$ \\
\hline JEL Kodu: & etmektedir. İki Aşamalı Sistem Genelleştirilmiş Momentler Metodu'nun \\
\hline O44, 053, Q58 & kullanıldığı çalışmadan elde edilen bulgular Düzey 2 bölgeleri açısından \\
\hline Anahtar Kelimeler: & Türkiye'de ÇKE hipotezinin geçerli olmadığını göstermektedir. Ayrıca enerji \\
\hline $\begin{array}{l}\text { Çevresel Kuznets } \\
\text { Eğrisi, Kamu }\end{array}$ & $\begin{array}{l}\text { tüketimi çevre kirliliğini istatistiksel olarak anlamlı ve pozitif etkilerken } \\
\text { ticari açıklık negatif etkilemektedir. Ancak çevre koruma harcamalarının }\end{array}$ \\
\hline $\begin{array}{l}\text { Harcamaları, Ekonomik } \\
\text { Büyüme, Bölgesel }\end{array}$ & çevre kirliliği üzerinde istatistiksel olarak anlamlı etkileri \\
\hline Kalkınma, Dinamik & bulunmamaktadır. Bu sonuçlar, çevre kalitesini artırmaya yönelik bölgesel \\
\hline Panel Veri Analizi & $\begin{array}{l}\text { düzeyde uygulanan iktisadi ve mali politikaların etkinliğinin artırılması } \\
\text { gerektiğini ortaya koymaktadır. }\end{array}$ \\
\hline
\end{tabular}

\section{Giriş}

Sanayi devriminden sonra hızla artan doğal kaynak tüketimi ile birlikte ekonomik büyüme ve çevresel bozulma arasındaki ilişki daha çok ilgi görmeye başlamıştır. Ekonomik büyüme pahasına çevresel bozulmanın göz ardı edilmesi ve politika yapıcıların çevreyi korumaya yönelik herhangi bir girişimde bulunmaması özellikle fosil yakıtlarına bağı olarak ortaya çıkan sera gazı emisyonlarının artmasına neden olmuştur. Günümüzde ise çevre sorunlarının kontrol edilemeyecek boyutlara ulaşması ve iklim değişikliğinin küresel bir sorun haline gelmesi nedeniyle birtakım politika tedbirleri üzerinde tartışmalar yoğunlaşmıştır. Bu doğrultuda daha önceleri çevreyi göz ardı eden ekonomik kalkınma politikaları yerine çevresel sorunları da dikkate alan sürdürülebilir ekonomik kalkınma politikalarının uygulanmasına yönelik ağılıklı bir görüş oluşmuştur. Diğer taraftan dünyada doğal kaynakların azalması ve toplumun çevre konusundaki hassasiyetinin giderek artması nedeniyle politika yapıcılar üzerinde büyük bir baskı oluşmaya başlamıştır. Bu durum ise çevre kirliliğini azaltmaya yönelik modern iktisadi ve mali politikaların hayata geçirilmesini teşvik etmiştir.

Küresel gelişmelere paralel olarak Türkiye'de ekonomik kalkınmanın gerçekleşmesi için hızlı bir sanayileşme sürecine girilmiş, nüfus hızlı bir şekilde artmış ve kontrolsüz kentleşme gerçekleşmiştir. Bu durum ise enerjiye olan ihtiyacı her geçen gün artırmış ve buna bağlı olarak önemli çevre sorunları ortaya çıkmaya başlamıştır. Öte yandan 1980 sonra uygulanan dışa açık politikalar çevre kalitesini doğrudan veya dolaylı olarak etkilemiştir. Bu gelişmeler Türkiye'de de çevrenin korunmasına yönelik iktisadi ve mali politikaların hayata geçirilmesi yönündeki tartışmaların artmasını sağlamıştır. Ancak bu politikaların etkin olabilmesi için çevre sorunlarına neden olan faktörlerin doğru bir şekilde analiz edilmesi gerekmektedir. Bu doğrultuda dünyada ve Türkiye'de gelir-çevre ilişkisine yönelik yapılan çalışmalarda özellikle Grossman \& 
Krueger (1991) tarafından geliştirilen Çevresel Kuznets Eğrisi (ÇKE) hipotezi sıklıkla test edilmektedir. ÇKE hipotezinde ülkelerin gelir düzeyleri ve ortaya çıkan çevresel tahribat arasında bir ilişki kurulmaktadır. Ayrıca gelir haricindeki değişkenlerle model genişletilerek çevre kirliliğinin belirleyicilerine yönelik bulgular elde edilebilmektedir.

Ekonomik büyüme ve çevresel bozulma arasındaki ilişkiyi özellikle ÇKE hipotezi çerçevesinde Türkiye için araştıran çalışmalar son dönemde artmaya başlamıştır (Bkz. Atıcı \& Kurt 2007; Başar \& Temurlenk, 2007; Halicioglu, 2009; Saatçi \& Dumrul 2011; Dam vd., 2013; Çil Yavuz, 2014; Kocak, 2014; Balıbey, 2015; Erdoğan vd., 2015; Artan vd., 2015; Gozgor \& Can, 2016; Kılıç \& Akalın, 2016; Lebe 2016; Çağlar \& Mert 2017; Katircioglu \& Taşpinar, 2017; Güney 2018; Güriş \& Şak, 2019; Pata, 2019). Türkiye üzerine yapılan çalışmalar incelendiğinde çalışmaların genellikle ülke düzeyinde olduğu yerel ve bölgesel çevre sorunları üzerine analiz yapan ampirik çalışmaların oldukça sınırlı olduğu görülmektedir. Ancak sınırlı sayıda da olsa ekonomik büyüme ve çevresel bozulma arasındaki ilişkiyi ÇKE hipotezi kapsamında bölgesel düzeyde araştıran çalışmalar bulunmaktadır (Bkz. Akyıldız, 2008; Akbostancı vd.,2009; Çatık vd., 2016; Güçlü, 2016; Karaçayır \& Güney 2016; Ayyıldız \& Gürler, 2017;Tuzcu \& Usupbeyli, 2018; Şahin, 2018; Deveci \& Sakallı, 2019).

Sürdürülebilir ekonomik kalkınmayı ulusal düzeyde gerçekleştirebilmenin yolu bölgesel düzeyde uygulanan etkin iktisadi ve mali politikalardan geçmektedir. Dolayısıyla bu konuda yapılacak bölgesel çalışmaların artırılması ve elde edilen bulgular ışı̆̆ında politika önerilerinde bulunulması gerekmektedir. Bu çalışmada ÇKE hipotezi Türkiye için bölgesel düzeyde test edilirken gelir, enerji tüketimi, ticari açıklık ve çevre koruma harcamalarının çevre kirliliği üzerindeki etkileri araştırılmıştır. 2007-2019 döneminin analiz edildiği çalışmada iki aşamalı sistem-GMM tahmini yapılmıştır. Türkiye'de sınırlı sayıda olan bölgesel düzeyde ÇKE hipotezini test eden çalışmalarda dinamik panel veri analizinin kullanılmadığı dikkatleri çekerken söz konusu çalışmalarda yer alan modellerde çevre koruma harcamaları yer almamaktadır. Bu çalışma hem yöntem hem de model olarak söz konusu literatüre katkı sağlamayı hedeflemektedir. Çalışmanın giriş bölümünün ardından ÇKE hipotezi ile ilgili teorik bilgiler ve bu konuda yapılan ampirik çalışmalar aktarılmıştır. Ardından Türkiye'de çevre kirliliğine dair ulusal ve bölgesel göstergeler ortaya koyulmuştur. Daha sonrasında bu çalışmada kullanılan model, veri seti ve uygulanacak yöntem hakkında bilgiler verilmiştir. Akabinde ise dinamik panel veri analizinden elde edilen ampirik bulgular sunulmuştur. Sonuç kısmında elde edilen bulgular yorumlanarak birtakım politika önerileri yapılmıştır.

\section{Teori ve Literatür}

\section{1. ÇKE Hipotezi: Teorik Arka Plan}

Yüksek yaşam standardına ulaşmak ve küresel yoksulluğu azaltmak adına yapılan bazı uygulamalar doğal kaynakların sınırsız bir şekilde kullanılmasına ve biyosferde geri dönülemez kayıpların oluşmasına neden olmuştur (Shahbaz vd., 
2017:2). Çevre kalitesinin küresel çapta bozulması ve buna bağlı olarak çevre sorunlarına ilişkin kamuoyu endişesinin artması ise çevresel bozulmanın nedenlerini anlamaya yönelik çabaların artmasını sağlamıştır. 1990'lar ile birlikte çevrenin ekonomik büyüme ile bağlantısı oldukça fazla tartışmaya yol açmış ve son dönemlerde kirlilik ve büyüme üzerine yapılan çalışmalar oldukça artmıştır (Dinda, 2004: 431-432).

Ekonomik büyüme ve çevre kirliliği arasındaki ilişki ÇKE hipotezi ile açıklanmakta ve temelde Kuznets (1955)'in yapmış olduğu çalışmaya dayanmaktadır. Gelir eşitsizliği ve ekonomik büyüme arasındaki ilişkiyi açıklamaya çalışan Kuznets (1955)'e göre ekonomik büyüme ve gelir eşitsizliği arasında ters yönlü bir ilişki bulunmaktadır. Kuznets (1955) gelir eşitsizliğinin ekonomik büyümenin ilk aşamalarında arttığını ancak belirli bir eşikten sonra azaldığını belirtmektedir. Kuznets (1955)'in çalışmasından yola çıkarak Grossman \& Krueger (1991) tarafından geliştirilen ÇKE hipotezi ise çevresel bozulmaya neden olan çeşitli faktörler ile kişi başına düşen gelir arasında ilişki kuran bir hipotezdir (Stern, 2004:1419). Bu hipoteze göre çevresel bozulma, ekonomik büyümenin ilk aşamalarında kişi başına düşen gelir ile birlikte artarken belirli bir eşiğe ulaştıktan sonra azalmaktadır (Apergis \& Ozturk, 2015: 16). Bu durum ise kişi başına gelir ile doğal kaynakların kullanımı ve atık emisyonları arasında ters $U$ şeklinde bir ilişkinin ortaya çıkmasına neden olmaktadır (Sharma, 2011: 376).

ÇKE hipotezinin geleneksel modeli (1) numaralı denklemde gösterilen karesel form şeklinde olup çevresel tahribat ile gelir arasındaki ilişkiyi açıklamaktadır. Geleneksel form haricinde (2) numaralı denklemde gösterilen kübik form ile de ÇKE hipotezi test edilmektedir. Bu denklemlerde $y$ çevresel kirliliği, $x$ geliri ve $z$ ise gelir haricinde çevresel tahribatı etkileyen faktörleri göstermektedir. $\beta^{\prime}$ nın almış olduğu katsayı değerleri ÇKE hipotezinin geçerliliğine ilişkin bilgi sunmaktadır. Karesel formu ifade eden (1) numaralı denklemde $\beta_{1}>0$ ve $\beta_{2}<0$ ise gelir ve çevre kirliliği arasında ters $U$ şeklinde bir ilişki söz konusudur. Bu durumda ÇKE hipotezinin geçerli olduğu sonucuna ulaşılmaktadır (Choi vd., 2010:8)

$$
\begin{aligned}
& y_{i t}=\alpha_{i}+\beta_{1} x_{i t}+\beta_{2} x_{i t}^{2}+\beta_{3} z_{i t}+\varepsilon_{i t} \\
& y_{i t}=\alpha_{i}+\beta_{1} x_{i t}+\beta_{2} x_{i t}^{2}+\beta_{3} x_{i t}^{3}+\beta_{4} z_{i t}+\varepsilon_{i t}
\end{aligned}
$$

(2) numaralı denklemde gösterilen kübik formda ise $\beta$ katsayısının aldığı değerleri Dinda (2004) şu şekilde açıklamaktadır:

i. $\quad \beta_{1}=\beta_{2}=\beta_{3}=0$ ise $x$ ve $y$ arasında herhangi bir ilişki yoktur.

ii. $\quad \beta_{1}>0$ ve $\beta_{2}=\beta_{3}=0$ ise $x$ ve $y$ arasında artan doğrusal bir ilişki vardır.

iii. $\beta_{1}<0$ ve $\beta_{2}=\beta_{3}=0$ ise $x$ ve $y$ arasında azalan doğrusal bir ilişki vardır.

iv. $\quad \beta_{1}>0, \beta_{2}<0$ ve $\beta_{3}=0$ ise ters $U$ şeklinde bir ilişki vardır. (ÇKE)

v. $\beta_{1}<0, \beta_{2}>0$ ve $\beta_{3}=0$ ise $U$ şeklinde bir ilişki vardır.

vi. $\quad \beta_{1}>0, \beta_{2}<0$ ve $\beta_{3}>0$ ise $N$ şeklinde bir ilişki vardır.

vii. $\beta_{1}<0, \beta_{2}>0$ ve $\beta_{3}<0$ ise ters $N$ şeklinde bir ilişki vardır.

ÇKE hipotezi ortaya atıldığı günden itibaren birçok araştırmacı tarafından hem karesel form hem de kübik formda test edilmiş ve son dönemde oldukça popüler hale 
gelmiştir. Bu yüzden ÇKE hipotezi ile ilgili literatür oldukça geniş ve kapsamlıdır. Ancak bir sonraki bölümde daha çok bu çalışmada kullanılan değişkenler dikkate alınarak seçilmiş literatür oluşturulmuştur.

\subsection{Literatür}

ÇKE hipotezinin geçerliliğine ilişkin çalışmalarda çevresel tahribatı etkileyen temel değişkenler arasında GSYH ve enerji tüketimi dikkatleri çekmektedir. Örneğin Pao \& Tsai (2010) BRICS ülkelerinde, Arouri vd. (2012) ve Cheikh vd. (2021) MENA ülkelerinde, Heidari vd. (2015) ASEAN ülkelerinde, Balado-Naves vd. (2018) 173 ülkede, enerji tüketiminin ve GSYH'nin karbondioksit emisyonunu artırdığı sonucuna ulaşmışlardır. Ayrıca bu çalışmalarda ÇKE hipotezinin geçerliliği kanıtlanmıştır. Acaravci \& Ozturk (2010) ise enerji tüketimi ve GSYH'nin karbondioksit emisyonu üzerinde pozitif etkilerini yakalarken ÇKE hipotezinin geçerliliği açısından ülkeden ülkeye farklılaşan sonuçlar elde etmişlerdir. Çevre kirliliğini etkileyen ana faktörler arasında enerji tüketimi ve reel gelir bulunurken bu değişkenler dışında da gelir-enerji-çevre ilişkisini etkileyen değişkenler bulunmaktadır. Dolayısıyla doğru bir sonuca ulaşmak için inmal edilen değişkenlerin modele eklenmesi gerekmektedir (Le \& Ozturk, 2020: 22681).

Bu doğrultuda son dönem çalışmalarda özellikle ticari açıklık değişkeni de ÇKE hipotezini test eden çalışmalarda kullanılmaktadır. Ancak ticari açıklığın kirlilik üzerindeki etkisi tartışmalıdır. Ticari açıklığın enerji yoğun sektörlerde üretilen mallar nedeniyle kirliliği artırıc bir etkisi bulunabilmektedir. Bu durumu destekler şekilde Kasman ve Duman (2015) yeni AB üyesi ülkelerde, Ozatac vd. (2017) ise Türkiye'de ticari açıklığın, Bento \& Moutinho (2016) ise İtalya'da uluslararası ticaretin karbondioksit emisyonunu pozitif etkilediği sonucuna varmıştır. Ancak üretim sektöründe geliştirilen teknolojilerle birlikte çevreyi daha az kirletecek ticari ilişkiler de kurulabilmektedir. Bu şekildeki ticari faaliyetler sonucunda özellikle gelişmiş ülkelerden gelişmekte olan ülkelere doğru enerji kullanımını ve kirliliği azaltan teknoloji yayılımı gerçekleşebilmektedir (Zafar vd., 2019:15163). Bu durumu destekler şekilde Jebli vd. (2016) OECD ülkelerinde, Sinha vd. (2017) N11 ülkelerinde, Sinha \& Shahbaz (2018) Hindistan'da, Zafar vd. (2019) ise yükselen ekonomilerde ticari açıklığın karbondioksit emisyonunu negatif etkilediği sonucuna varmışlardır. Ayrıca bu çalışmalarda ÇKE hipotezinin geçerli olduğu sonucuna da varılmıştır. Bununla birlikte Pata \& Çağlar (2021) Çin üzerine yaptıkları çalışmalarında ticari açıklığın kirlilik üzerinde pozitif etkisi olduğunu tespit ederlerken ÇKE hipotezinin geçerli olmadığı bulgusuna ulaşmışlardır.

Son dönemlerde çevresel tahribat ile uygulanan kamu politikaları da yakın ilişki içerisindedir. Çevresel tahribatın olumsuz dışsallıkları nedeniyle kaynaklar etkin bir şekilde kullanılamamakta ve bu durum devletin piyasaya müdahalesini zorunlu kılmaktadır. Çevre ve çevre koruma kamusal mal özelliği taşıdığından çevrenin korunması ve dışsallıkların içselleştirilmesi için çevresel düzenlemeye ihtiyaç duyulmaktadır (Mutlu: 2006:62). Özellikle çevre, büyüme ve kirlilik kavramlarının 
toplum tarafından ilgi görmeye başlaması devlet tarafından belirlenen çevresel kamu malları ile çevrenin korunmasına yönelik politikaların daha yoğun şekilde hayata geçirilmesini sağlamaktadır. Bu doğrultuda uygulanan maliye politikaları gelir etkisi, teknik etki ve bileşim etkisi ile çevre kalitesini etkileyebilmektedir. Gelir etkisine göre gelirde meydana gelen bir artış çevresel kalite konusunda toplumun endişelerinin artmasını sağlamaktadır. Artan kamu harcama talepleri ise kirlilik üzerinde etkili olabilmektedir. Teknik etkiye göre, devletin yapmış olduğu mali harcamalar işgücü verimliliğini artırmaktadır. Bu durum ise çevre kalitesini olumlu yönde etkilemektedir (Kamal vd., 2021:2). Bileşim etkisine göre kamu harcamalarının yeniden tahsisi ile birlikte fiziksel sermaye yerine beşeri sermayenin artışı desteklenebilmektedir. Bu durum ise çevre kalitesini artıran bir çıktı bileşiminin oluşmasını teşvik etmektedir (Lopez vd., 2011: 181).

$\mathrm{Bu}$ doğrultuda devletin çevre kirliliğini azaltmak için uygulamaya koyduğu politikalardan biri ise çevre koruma harcamalarıdır. Ancak çevre koruma harcamaları ile kirlilik arasındaki ilişkiyi araştıran çalışmalarda da net bir görüş birliğinden bahsetmek mümkün değildir. Huang (2018) yaptığı çalışmasında çevrenin korunmasına yönelik kamu harcamalarının Çin'de kirlilik düzeyini azalttığı sonucuna varırken giderek artan kirlilikle başa çıkmanın etkili yollarından birinin çevre koruma harcamaları olduğunu vurgulamıştır. Benzer şekilde Bostan vd. (2016) 18 AB üyesi ülkede, Ercolano \& Romano (2017) Avrupa'da, Gholipour \& Farzanegan (2018) ise MENA ülkelerinde çevreyi korumaya yönelik kamu harcamalarının çevresel performansı olumlu etkilediğini ortaya koymuşlardır. Öte yandan yerel yönetimler ekonomik büyümeyi artırmak amacıyla çevre kirliliğine yol açan endüstriyel kalkınmaya destek vermektedirler (He vd., 2018:7456). Bu durumda çevre koruma harcamaları etkinliğini yitirmektedir. Örneğin Yavan \& Hotunluoğlu (2018) Türkiye'de belediyelerin yapmış olduğu çevre harcamaları ile hava kirliliği arasında pozitif bir ilişki elde etmişlerdir. Bu sonucu destekler şekilde Moshiri \& Daneshmand (2020) ise İran'daki çevre koruma harcamalarının kirliliği azaltmada etkin olmadığı sonucuna varmışlardır. Bu sonuçlar çevre koruma harcamalarının tek başına kirliliği azaltmada yetersiz kalabildiğini göstermektedir.

\section{Türkiye'de Son Dönem Çevresel Göstergeler}

Hızlı nüfus artışı, kontrolsüz kentleşme ve ekonomik faaliyetlerin artması tüm dünyada olduğu gibi Türkiye'de de çevresel göstergeleri etkilemektedir. Ancak sürdürülebilir bir ekonomik kalkınmaya sahip olmak için uzun dönemli çevre politikalarına intiyaç duyulmaktadır. Bu doğrultuda ampirik analize geçmeden önce Türkiye'de çevresel göstergelere kısaca bakmakta yarar vardır. Türkiye'de bölgesel düzeyde en önemli kirlilik göstergeleri partiküler madde (PM10) ve kükürtdioksit $\left(\mathrm{SO}_{2}\right)$ konsantrasyonu olduğundan bu göstergelerin son dönemdeki ortalama değerleri Şekil 1 'de gösterilmiştir. 
Şekil 1. Türkiye'de Ortalama PM10 ve $\mathrm{SO}_{2}$ Konsantrasyonları $\left(\mu \mathrm{g} / \mathrm{m}^{3}\right)$

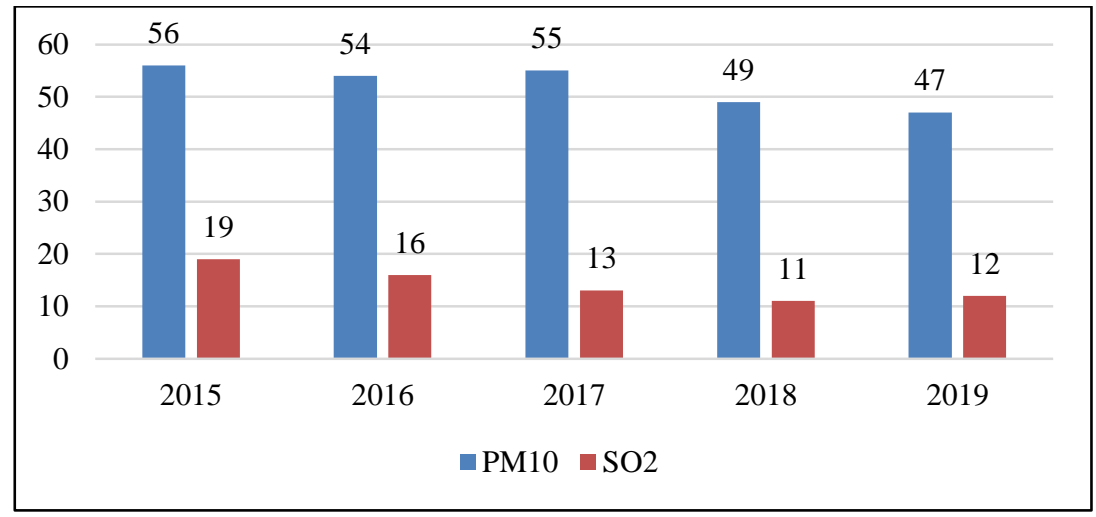

Kaynak: Çevre ve Şehircilik Bakanlığı, ÇED

Türkiye'de ortalama PM10 değerlerinin genel olarak ortalama $\mathrm{SO}_{2}$ değerlerinden yüksek olduğu Şekil 1'de görülebilmektedir. Öte yandan ortalama PM10 ve $\mathrm{SO}_{2}$ değerlerinin son yıllardaki durumuna bakıldığında ise her iki değişkenin de genel olarak azalma eğiliminde olduğu dikkatleri çekmektedir. Ancak son yayımlanan verilere göre her iki değişken $A B$ tarafından belirlenen sınır değerlerini aşmaktadır (Çevre ve Şehircilik Bakanlığı,2020:12). Bu durum Türkiye'nin hava kalitesi açısından iyi bir tablo çizmediğini ancak değişkenlerdeki eğilimin hava kalitesi açısından olumlu olduğu şeklinde yorumlanmaktadır.

Öte yandan kirlilik göstergeleri açısından Türkiye genelindeki eğilime ek olarak bölgesel düzeydeki eğilimleri irdelemekte yarar vardır. Şekil 2 incelendiğinde Türkiye'nin Düzey 2 bölgelerinde genel olarak kişi başına düşen PM10 ve $\mathrm{SO}_{2}$ değerlerinin azalma eğiliminde olduğu dikkatleri çekmektedir. Ancak bazı bölgelerde genel eğilimin dışında bir durum da söz konusudur. Örneğin Tekirdağ, Edirne, Kırklareli alt bölgesinde kişi başına düşen PM10 değeri azalma eğiliminde iken kişi başına düşen $\mathrm{SO}_{2}$ değeri artış eğilimindedir. Diğer taraftan Erzurum, Erzincan, Bayburt alt bölgesinde araştırma dönemi boyunca kirlilik göstergeleri çok büyük değişim göstermemiştir. Şekil 2'de dikkat çeken bir diğer nokta ise sanayi bölgelerinde $\mathrm{SO}_{2}$ ve $\mathrm{PM} 10$ değerlerinin azalma eğiliminde olmasıdır. Örneğin İstanbul alt bölgesi ve Kocaeli, Sakarya, Düzce, Bolu, Yalova alt bölgelerinde kirlilik göstergeleri açısından kararlı bir azalma eğilimi söz konusudur. Öte yandan gelir düzeyi düşük bölgelerde kirlilik göstergelerindeki azalma eğilimi de dikkat çekicidir. Türkiye İstatistik Kurumu (TÜiK) 2019 yılı verilerine göre kişi başına düşen geliri en düşük bölge olan Şanlıurfa, Diyarbakır alt bölgesinde PM10 ve $\mathrm{SO}_{2}$ değerlerindeki azalma eğilimi gelişmiş bölgelerdeki azalma eğilimine göre daha net bir şekilde hissedilmektedir. Bu sonuçları Türkiye genelinde ortaya çıkan eğilimin bölgesel yansımaları olarak yorumlamak mümkündür. Ancak grafiksel olarak verilen bu sonuçlar ampirik analiz öncesi sadece önsel bilgi sunmaktadır. Çevresel değişkenleri etkileyen faktörler hakkında bilgi vermemektedir. 
Şekil 2. Düzey 2 Bölgelerine Ait Kişi Başına Düşen $\mathrm{PM10}$ ve $\mathrm{SO}_{2}$ Ortalamaları $\left(\mu \mathrm{g} / \mathrm{m}^{3}\right)$

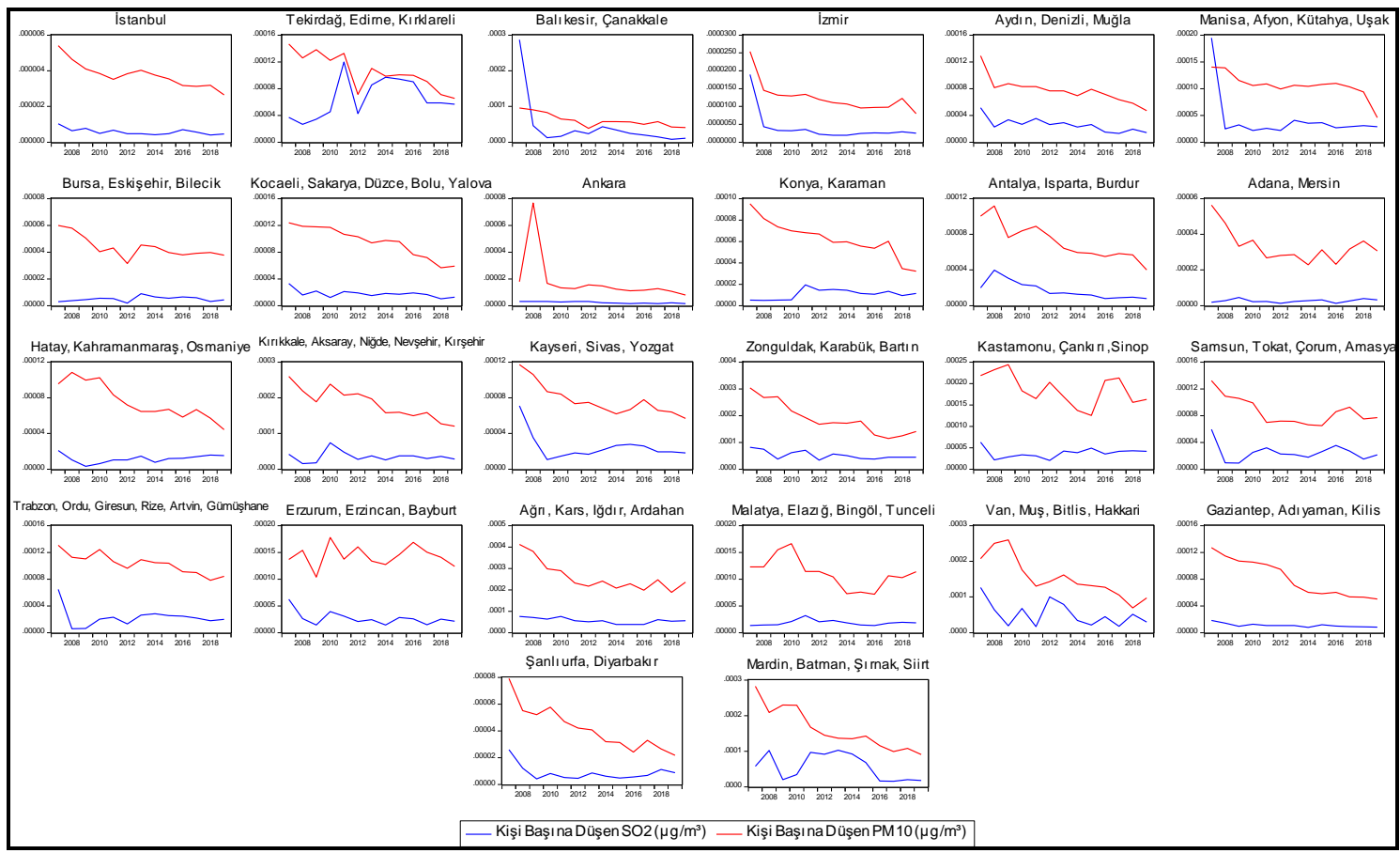

Kaynak: Çevre ve Şehircilik Bakanlığı

\section{Model ve Veri Seti}

Bu çalışmada Türkiye'nin 26 adet Düzey 2 bölgesi dikkate alınarak ÇKE hipotezi test edilmiştir. ÇKE hipotezini test etmek için (1) numaralı denklemde gösterilen geleneksel karesel form dikkate alınarak analiz gerçekleştirilmiştir. Bağımlı değişkenin gecikmeli değerinin bağımsız değişken olarak yer aldığı iki adet dinamik panel veri modeli oluşturulmuştur. Modeller oluşturulurken ÇKE hipotezini test etmek için Pao \& Tsai (2010)'nin çalışmasında olduğu gibi gelir, Kasman \& Duman (2015)'in çalışmasında olduğu gibi enerji tüketimi ve ticari açıklık oranı, Moshiri \& Daneshmand (2020)'in çalışmasında olduğu gibi çevre koruma harcamaları değişkenleri modellere eklenmiştir. (3) ve (4) numaralı denklemlerde bölgeler $i$, araştırma dönemi ise $t$ ile gösterilirken $\alpha_{i t}$ sabit parametreyi $\varepsilon_{i t}$ ise hata terimlerini ifade etmektedir. Modellerde kullanılan değişkenlere ait özet bilgiler Tablo 1'de sunulmuştur.

Model 1:

$\operatorname{LnKBPM10} 0_{i t}=\alpha_{i t}+\beta_{1} \operatorname{LnKBGSYH_{it}}+\beta_{2}(\operatorname{LnKBGSYH})_{i t}^{2}+\beta_{3} E T_{i t}+\beta_{4} T A_{i t}+$ $\beta_{5} \ln K B C K H_{i t}+\beta_{6} \ln K B P M 10_{i t-1}+\varepsilon_{i t}$

Model 2:

$\operatorname{LnKBSO2}_{i t}=\alpha_{i t}+\beta_{1} \operatorname{LnKBGSYH_{it}}+\beta_{2}(\operatorname{LnKBGSYH})_{i t}^{2}+\beta_{3} E T_{i t}+\beta_{4} T A_{i t}+$ $\beta_{5} \operatorname{lnKBCKH_{it}}+\beta_{6} \operatorname{LnKBSO} 2_{i t-1}+\varepsilon_{i t}$

Türkiye'de bölgesel düzeyde çevre kirliliğinin göstergesi olarak kullanılabilecek en kapsamlı veriler $\mathrm{PM} 10$ ve $\mathrm{SO}_{2}$ konsantrasyonu olarak dikkatleri çekmektedir. $\mathrm{Bu}$ 
nedenle Model 1'de bağımlı değişken olarak kişi başına düşen PM10 konsantrasyonu Model 2'de ise kişi başına düşen $\mathrm{SO}_{2}$ konsantrasyonu kullanılmıştır. PM10, özellikle sanayi, taşıt emisyonları, fosil yakıtlar ve ikincil kimyasal reaksiyonlar nedeniyle ortaya çıkarken $\mathrm{SO}_{2}$ de benzer şekilde fosil yakıt yanması ve taşıt emisyonları nedeniyle ortaya çıkarak kirliliğe neden olmaktadır. İllerdeki ölçüm merkezlerinden elde edilen ortalama PM10 verisi 2007 yılından itibaren Çevre ve Şehircilik Bakanlığı tarafından yayımlanmaktadır. Daha önceleri Sağlık Bakanlığı ve Tüik tarafından yayımlanan PM10 verisi hem güncel verilerle kıyaslanabilir durumda olmadığından hem de tüm bölgelere ilişkin 2007 yılından önceki yıllarda büyük veri eksikliğinden dolayı çalışma dönemi 2007 yılından itibaren başlatılmıştır.

Tablo 1: Değişkenlere Ait Açıklayıcı Bilgiler

\begin{tabular}{|c|c|c|}
\hline Değişken & Açıklama & Kaynak \\
\hline LnKBPM10 & Kişi Başına Düşen PM10 Konsantrasyonu- $\left(\mu \mathrm{g} / \mathrm{m}^{3}\right)$ & $\begin{array}{l}\text { Çevre ve Şehircilik } \\
\text { Bakanlığı }\end{array}$ \\
\hline LnKBSO2 & Kişi Başına Düşen SO2 Konsantrasyonu- $\left(\mu \mathrm{g} / \mathrm{m}^{3}\right)$ & $\begin{array}{l}\text { Çevre ve Şehircilik } \\
\text { Bakanlığı }\end{array}$ \\
\hline LnKBGSYH & Kişi Başına Düşen Reel GSYH-(Türk Lirası) & $\begin{array}{l}\text { Türkiye istatistik } \\
\text { Kurumu }\end{array}$ \\
\hline$(L n K B G S Y H)^{2}$ & Kişi Başına Düşen Reel GSYH'nin Karesi-(Türk Lirası) & $\begin{array}{l}\text { Türkiye istatistik } \\
\text { Kurumu }\end{array}$ \\
\hline$E T$ & Sanayi Elektrik Tüketiminin Toplam Elektrik Tüketimine Oranı-(\%) & $\begin{array}{l}\text { Türkiye istatistik } \\
\text { Kurumu }\end{array}$ \\
\hline$T A$ & ihracat ve ithalat toplamının GSYH'ye Oranı- (\%) & $\begin{array}{l}\text { Türkiye istatistik } \\
\text { Kurumu }\end{array}$ \\
\hline $\operatorname{LnKBCKH}$ & Kişi Başına Düşen Reel Çevre Koruma Harcamaları- (Türk Lirası) & $\begin{array}{l}\text { Hazine ve Maliye } \\
\text { Bakanlığı }\end{array}$ \\
\hline
\end{tabular}

Çalışmada kullanılan bağımsız değişkenlerden kişi başına düşen GSYH verisi ise TÜik'ten cari olarak TL cinsinden elde edilmiştir. Ardından Türkiye Cumhuriyet Merkez Bankası Elektronik Veri Dağıtım Sistemi (EVDS) tarafından yayımlanan Düzey 2 bölgelerine ilişkin TÜFE verisi ile reel hale getirilmiştir. TÜiK'te bölgesel GSYH verileri şuan için 2019 yılına kadar elde edilebilir olduğundan çalışma 2007-2019 dönemi ile sınırlandırılmıştır. Enerji tüketimi verisi olarak sanayi işletmelerinin kullanmış olduğu elektrik tüketim oranı kullanılırken ticari açıklık verisi olarak ihracat ile ithalat toplamının GSYH'ye oranı kullanılmıştır. Enerji tüketimi ve ticari açıklık verileri de TÜik'ten elde edilmiştir. Son olarak kişi başına düşen çevre koruma harcamaları verisi ise Hazine ve Maliye Bakanlığı Muhasebat Genel Müdürlügü internet sitesinde yer alan iller itibariyle merkezi yönetim bütçe istatistiklerinden elde edilmiş ve toplulaştırılarak Düzey 2 bölgelerine uyarlanmıştır. Kişi başına düşen çevre koruma harcamaları verisi de bölgesel TÜFE verisi ile reel hale getirilmiştir. Çalışmada sanayi elektrik tüketim oranı ve ticari açıklık oranı haricindeki tüm değişkenlerin doğal logaritmaları alınarak analiz gerçekleştirilmiştir. 


\section{Yöntem}

Panel veri tekniğinin kullanıldığı modellerde genel olarak sabit etkiler ve tesadüfi etkiler model tahmincilerine dayanan statik modeller kullanılmaktadır (Keyifli \& Akdede, 2017:85). Ancak statik modeller dinamik ilişkileri göz ardı ettiğinden son dönemlerde dinamik panel veri yöntemleri sıklıkla kullanılmaya başlanmıştır. Dinamik panel veri analizleri temelde dağıtılmış gecikmeli panel veri modelleri ve otoregresif panel veri modelleri olarak iki gruba ayrılmaktadır. Genel olarak dinamik panel veri modeli denilince otoregresif panel veri modelleri akla gelmektedir. Otoregresif panel veri modellerinde bağımlı değişkenin gecikmeli değerleri açıklayıcı değişkenler olarak modele dâhil edilmektedir. Bu durumda modelde bağımsız değişken olarak yer alan bağımlı değişkenin gecikmeli değerleri ile hata terimi arasında korelasyon oluşmakta ve bu durum içsellik sorununu ortaya çıkarmaktadır (Yerdelen Tatoğlu, 2013:103). Arellano \& Bond (1991)'un Fark GMM, Arellano \& Bover (1995) ile Blundell \& Bond (1998)'un sistem-GMM tahmincileri araç değişken kullanımı ile bu sorunun üstesinden gelmektedirler. Ancak zaman serileri süreklilik gösterdiğinde ve zaman periyotlarının sayısı az olduğunda fark GMM tahmincilerinin performansı düşmektedir. Bunun nedeni serilerin gecikmeli değerlerinin farkı alınmış eşitlikler için zayıf araçlar sağlamasıdır. Ayrıca birimlere özgü etkileri ortadan kaldırmak için yapılan fark alma süreci, seviye değerlerdeki ülkelere özgü farklılıklara dair bilgileri de yok etmektedir (Fukase, 2010: 202).

Sistem-GMM yaklaşımı temelde fark GMM yaklaşımını dikkate almakta ancak daha iyi performans sergilemektedir (Arellano \& Bover, 1995; Blundell \& Bond, 1998). Bunun nedeni Sistem-GMM yaklaşımında birinci fark yerine "ortogonal sapmalar" dönüşümünün kullanılmasıdır. Bu yöntemde bir değişkenin tüm mümkün gelecek değerlerinin ortalamasının farkı alınmaktadır. Böylelikle birinci farklar yönteminde ortaya çıkan veri kaybı azaltılmaktadır (Yerdelen Tatoğlu, 2013:86). Sistem-GMM tahmincisinin yüksek etkinliğe ve daha düşük sapmaya sahip olması fark GMM tahmincisine göre daha çok tercih edilmesini sağlamaktadır. Dolayısıyla bu çalışmanın analizinde daha etkin sonuçlara ulaşmak için iki aşamalı sistem-GMM tahmincisi kullanılmıştır.

Öte yandan GMM tahmincisinin tutarlı olup olmadığını tespit etmek için otokorelasyonun varlığı ve araç değişkenlerin geçerliliği olmak üzere iki temel varsayımın sınanması gerekmektedir. Otokorelasyon sorununun tespiti için birinci mertebeden otokorelasyon yoktur şeklinde temel hipoteze sahip olan $A R(1)$ ve ikinci mertebeden otokorelasyon yoktur şeklinde temel hipoteze sahip olan $A R(2)$ testleri Arellano \& Bond (1991) tarafından önerilmektedir. Bu testler sonucunda etkin bir sonuca ulaşmak için birinci mertebeden otokorelasyon olsa bile ikinci mertebeden otokorelasyon olmaması gerekmektedir. Ayrıca araç değişkenlerin geçerliliğine ilişkin Sargan testi yapılmaktadır. Sargan testinde ise temel hipotez aşırı tanımlama kısıtlamaları geçerlidir şeklindedir. Eğer temel hipotez reddedilemezse seçilen araç değişkenlerin uygun olduğu sonucuna ulaşılmaktadır. 


\section{Ampirik Bulgular}

\subsection{Tanımlayıcı İstatistikler}

Bu bölümde öncelikle çalışmada kullanılan değişkenlere ilişkin ön bilgi edinmek amacıyla tanımlayıcı istatistiklere yer verilmiş ve Tablo 2'de sunulmuştur.

Tablo 2: Çalışmada Kullanılan Değişkenlere Ait Tanımlayıcı İstatistikler

\begin{tabular}{lllll}
\hline Değişkenler & Ortalama & Std. Sapma & Minimum & Maksimum \\
\hline KBPM10 & 0,0000978 & 0,0000681 & $2,64 \mathrm{e}-06$ & 0,0004114 \\
KBSO2 & 0,000026 & 0,0000287 & $3,98 \mathrm{e}-07$ & 0,0002872 \\
KBGSYH & 8638,009 & 3467,673 & 3154,684 & 20948,09 \\
ET & 42,44182 & 19,2095 & 5,819786 & 78,91242 \\
TA & 20,91613 & 19,29381 & 1,052485 & 83,5408 \\
KBCKH & 1,216329 & 1,267198 & 0,0010876 & 9,652221 \\
\hline
\end{tabular}

Tablo 2'den elde edilen bulgulara göre 2007-2019 döneminde kişi başına düşen en düşük PM10 değerine sahip bölge sıfıra çok yakın bir değerle 2019 yılında İstanbul alt bölgesi iken en yüksek $(0,0004)$ kişi başına düşen PM10 değerine sahip alt bölge 2007 yılında Ağrı, Kars, Iğdır, Ardahan alt bölgesidir. Öte yandan kişi başına düşen en düşük $\mathrm{SO}_{2}$ değerine sahip bölge sıfıra çok yakın bir değerle 2018 yılında yine İstanbul alt bölgesi iken kişi başına düşen en yüksek $\mathrm{SO}_{2}$ değerine $(0,0002)$ sahip bölge 2007 yılında Balıkesir, Çanakkale alt bölgesidir. Çalışmada bölgesel gelir düzeyinin göstergesi olarak kullanılan kişi başına düşen reel GSYH açısından en düşük değere $(3154,68)$ sahip bölge 2009 yılında Van, Muş, Bitlis, Hakkâri alt bölgesi iken en yüksek kişi başına düşen reel GSYH'ye $(20948,09)$ sahip bölge 2018 yılında İstanbul alt bölgesidir. Sanayi elektrik kullanım oranı en düşük $(5,8)$ bölge olarak 2007 yılında Van, Muş, Bitlis, Hakkâri alt bölgesi dikkatleri çekerken en yüksek $(78,9)$ sanayi elektrik kullanım oranı 2014 yılında Tekirdağ, Edirne, Kırklareli alt bölgesi olarak dikkatleri çekmektedir. Ticari açıklık oranına bakıldığında ise Türkiye'de ticari açıklık oranı en düşük $(1,05)$ bölge 2017 yılında Erzurum, Erzincan, Bayburt alt bölgesi iken ticari açıklık oranı en yüksek $(83,5)$ bölge 2018 yılında İstanbul alt bölgesidir. Son olarak, kişi başına düşen çevre koruma harcamaları en düşük $(0,001)$ bölge ise 2017 yılında Mardin, Batman, Şırnak, Siirt alt bölgesi olarak dikkatleri çekerken kişi başına düşen çevre koruma harcamaları en yüksek (9,652) bölge 2015 yılında Erzurum, Erzincan, Bayburt alt bölgesi olarak dikkatleri çekmektedir. 


\section{2. İki Aşamalı Sistem-GMM Tahmin Sonuçları}

Türkiye'de ÇKE hipotezi kapsamında gelir, enerji tüketimi, ticari açıklık ve çevre koruma harcamalarının çevre kirliliği üzerindeki etkisi dinamik panel veri yöntemi ile analiz edilmiştir. Bu doğrultuda yapılan iki aşamalı sistem-GMM tahmin sonuçları Tablo 3'te gösterilmiştir.

Tablo 3: İki Aşamalı Sistem-GMM Tahmin Sonuçları

\begin{tabular}{|c|c|c|c|c|}
\hline \multirow{2}{*}{$\begin{array}{l}\text { Bağımsız } \\
\text { Değişkenler }\end{array}$} & \multicolumn{2}{|c|}{$\begin{array}{c}\text { Model } 1 \\
\text { Bağımlı Değişken: LnKBPM10 }\end{array}$} & \multicolumn{2}{|c|}{$\begin{array}{c}\text { Model } 2 \\
\text { Bağımlı Değişken: LnKBSO2 }\end{array}$} \\
\hline & Katsayı & İstatistik & Katsayı & İstatistik \\
\hline LnKBGSYH & $\begin{array}{l}-0,3018^{*} \\
(0,000)\end{array}$ & $-5,17$ & $\begin{array}{l}-0,6852 * \\
(0,000)\end{array}$ & $-4,91$ \\
\hline$(\operatorname{LnKBGSYH})^{2}$ & $\begin{array}{l}0,0172 * \\
(0,003)\end{array}$ & 2,99 & $\begin{array}{l}0,0712^{* *} \\
(0,030)\end{array}$ & 2,17 \\
\hline$E T$ & $\begin{array}{l}0,0026^{*} \\
(0,000)\end{array}$ & 5,44 & $\begin{array}{l}0,0049 * \\
(0,000)\end{array}$ & 7,05 \\
\hline$T A$ & $\begin{array}{l}-0,0037^{*} \\
(0,000)\end{array}$ & $-4,85$ & $\begin{array}{l}-0,0066^{*} \\
(0,000)\end{array}$ & $-9,12$ \\
\hline $\operatorname{LnKBCKH}$ & $\begin{array}{l}-0,0055 \\
(0,252)\end{array}$ & $-1,15$ & $\begin{array}{l}0,0153 \\
(0,543)\end{array}$ & 0,61 \\
\hline $\operatorname{LnKBPM1O_{t-1}}$ & $\begin{array}{l}0,7932 * \\
(0,000)\end{array}$ & 16,56 & - & - \\
\hline $\operatorname{LnKBSO}_{t-1}$ & - & - & $\begin{array}{l}0,6872 * \\
(0,000)\end{array}$ & 17,93 \\
\hline
\end{tabular}

Diagnostik Testler

Sargan $(\chi 2)$ $92,13(0,100)$ $94,54(0,063)$

$A R(1)$ $-3,18(0,001)$ $-2,65(0,008)$

$A R(2)$

$1,23(0,220)$ $0,90(0,369)$

Wald ( $\chi 2)$ Olasilık $(0,000)$ $(0,000)$

*, ** işaretleri sırasıyla $\% 1$ ve $\% 5$ anlamlılık düzeylerini göstermektedir. Parantez içerisindeki değerler olasılık değerleridir.

Tablo 3'te yer alan Wald $\left(\chi^{2}\right)$ testine ait olasılık değerleri çalışmada kullanılan modellerin anlamlı olup olmadığını göstermektedir. Buna göre Model 1 ve Model 2 istatistiksel olarak \%1 düzeyinde anlamlıdır. Modellerde otokorelasyon sorunu olup olmadığını tespit etmek için ise $A R(1)$ ve $A R(2)$ testleri yapılmıştır. $A R(1)$ testinden elde 
edilen istatistik değerleri eksi işaretli olup \%1 düzeyinde anlamlı iken $A R(2)$ testinden elde edilen değer istatistiksel olarak anlamsızdır. Bu sonuca göre her iki modelde de birinci mertebeden otokorelasyon sorunu bulunmasına rağmen ikinci mertebeden otokorelasyon sorunu bulunmamaktadır. Diğer taraftan çalışmanın analizinde kullanılan araç değişkenlerin geçerliliğine ilişkin ise Sargan testi yapılmıştır. Aşırı tanımlama kısıtlamaları geçerlidir şeklinde temel hipoteze sahip olan Sargan ( $\chi 2$ ) testinden elde edilen bulgular her iki model için temel hipotezin \%5 anlamlılık düzeyinde reddedilemediğini bir diğer ifade ile modellerin tahmininde kullanılan araç değişkenlerin geçerli olduğunu göstermektedir.

İki aşamalı sistem-GMM tahmin sonuçlarının yer aldığı Tablo 3'e göre bağımlı değişken olarak Model 1'de yer alan LnKBPM10 ve Model 2'de yer alan LnKBSO2 değişkenlerinin gecikmeli değerleri söz konusu değişkenleri istatistiksel olarak anlamlı ve pozitif etkilemektedir. Diğer taraftan gelir düzeyini gösteren $L n K B G S Y H$ ve $(L n K B G S Y H)^{2}$ değişkenlerinin çevre kirliliği üzerindeki etkisine bakıldığında ise her iki model açısından da ÇKE hipotezinin desteklenmediği görülmektedir. Katsayı değerleri istatistiksel olarak anlamlı olmasına rağmen çevre kirliliğini LnKBGSYH değişkeni negatif, (LnKBGSYH) ${ }^{2}$ değişkeni ise pozitif etkilemektedir. (1) numaralı denklemde gösterilen karesel formda ÇKE hipotezinin geçerli olabilmesi için $\beta_{1}>0$ ve $\beta_{2}<0$ olması gerekmektedir. Ancak bu çalışmadan elde edilen bulgular hem Model 1 hem de Model 2 açısından bu şartın sağlanmadığını diğer bir ifade ile gelir ve çevre kirliliği arasında $U$ şeklinde bir ilişkinin söz konusu olduğunu ortaya koymaktadır. Dolayısıyla bu çalışmanın sonuçları Türkiye'nin Düzey 2 bölgelerinde 2007-2019 dönemi için ÇKE hipotezinin geçerli olmadığını göstermektedir. Her iki modelden elde edilen bulgular birbirini destekler niteliktedir. Bu durum ÇKE hipotezinin aksine bölgesel gelir düzeyi arttıkça ilk aşamada nispeten çevreyi daha az kirleten üretim tarzının benimsendiği şeklinde yorumlanabilir. Ayrıca bu sonuçlar gelir-çevre ilişkisine dair Türkiye'de bölgesel düzeyde çalışma yapan Güçlü (2016), Ayyıldız \& Gürler (2017) ile Tuzcu \& Usupbeyli (2018)'nin çalışmaları ile örtüşmektedir.

Modellerde enerji tüketimini temsilen yer alan sanayi elektrik tüketim oranı ise çevresel tahribatı istatistiksel olarak anlamlı ve pozitif etkilemektedir. Tüm dünyada ve özellikle Türkiye gibi gelişmekte olan ülkelerde ağırlıklı olarak fosil yakıtlara dayanan bir enerji tüketimi söz konusudur. Bağımlı değişken olarak modellerde kullanılan LnKBPM1O ve LnKBSO2 değişkenleri ise önemli ölçüde fosil yakıt tüketiminden etkilenmektedir. Dolayısıyla enerji tüketiminin çevre kirliliğini artırması teorik beklentilerle uyumlu bir bulgudur. Enerji tüketimi ve çevre ilişkisine dair bu bulgu ise Acaravci \& Ozturk (2010), Pao \& Tsai (2010), Arouri vd. (2012), Heidari vd. (2015), Balado-Naves vd. (2018), Cheikh vd. (2021)'nin çalışmaları ile örtüşmektedir.

Öte yandan bölgelerdeki ticari açıklık oranı ise çevre kirliliğini istatistiksel olarak anlamlı ve negatif etkilemektedir. Bu sonuç ise Türkiye'de bölgesel düzeyde ÇKE hipotezini test eden Şahin (2018)'in çalışması ile örtüşmektedir. Türkiye'de uzun yıllardır ithalata dayalı bir üretim anlayışı benimsenmiştir. Bu durumun dış ticaret dengesi açısından olumsuz bir yanı bulunsa da sanayileşmiş ülkelerden verimli ve çevre dostu ürünlerin ithal edilmesi çevre kalitesine olumlu yansıyabilmektedir. Ayrıca 
ihracatı artırmak için yapılan Ar-Ge ve inovasyon faaliyetlerinin de kirliliği azaltıcı etkileri bulunmaktadır. Dolayısıyla ticari performansını ve ticari açıklığını artıran, dünya ile daha fazla entegre olan ve bu sayede gelişmiş ülkelerle bilgi akışını sağlayabilen bölgelerin çevre kirliliği azalmaktadır. Dış ticaret açısından elde edilen bu bulgular Jebli vd.(2016), Sinha vd. (2017), Sinha \& Shahbaz (2018), Zafar vd. (2019)'nin elde ettikleri bulguları destekler niteliktedir.

Çevresel tahribatın önüne geçmek adına devlet tarafından uygulamaya koyulan çevre koruma harcamalarının ise teorik olarak çevre kirliliğini istatistiksel olarak anlamlı ve negatif etkilemesi beklenmektedir. Tablo 3'ten elde edilen bulgulara göre çevre koruma harcamalarının çevre kirliliği üzerindeki etkisi hem Model 1 hem de Model 2'de istatistiksel olarak anlamsızdır. Dolayısıyla Türkiye'de bölgesel düzeyde yapılan çevre koruma harcamalarının bölgelerdeki çevre kirliliğini azaltmada etkin olmadığı tespit edilmiştir. Bu sonuçlar Türkiye üzerine çalışma yapan Yavan \& Hotunluoğlu (2018)'nun çalışmasını destekler niteliktedir. Ayrıca Moshiri \& Daneshmand (2020)'ın çalışmasından elde edilen sonuçlar da bu çalışmada ortaya çıkan sonuçlarla örtüşmektedir.

\section{Sonuç}

Hızlı bir sanayileşme sürecinin yaşandığı Türkiye'de son dönemlerde enerji tüketiminde bir artış yaşanırken bu süreçle bağlantılı olarak çevre sorunlarının ortaya çıktığı görülmektedir. Bu bağlamda Türkiye için ÇKE hipotezini test eden çalışmalar her geçen gün artarken bölgesel düzeyde bu hipotezi test eden çalışmaların sınırlı olduğu dikkati çekmektedir. Bu durum Türkiye'de il veya bölgesel düzeydeki verilerin çok kısıtlı olmasından kaynaklanabilir. Ancak son yıllarda hem TÜik hem de ilgili bakanlıkların yayımladığı bölgesel istatistikler açısından olumlu gelişmeler yaşanmaktadır. Bu durum il ve bölgesel düzeyde yapılan çalışmalara yansımaya başlamıştır.

Bu çalışmada ÇKE hipotezi Türkiye'nin 26 adet Düzey 2 bölgesi açısından test edilmiştir. 2007-2019 dönemini kapsayan çalışmada dinamik panel veri yöntemlerinden biri olan iki aşamalı sistem-GMM yaklaşımı kullanılmıştır. Çalışmanın analizi için $\mathrm{PM} 10$ ve $\mathrm{SO}_{2}$ verilerinin bağımlı değişken olduğu iki ayrı model kurulmuştur. Modellerde çevre kirliliğini etkileyen değişkenler olarak gelir, enerji tüketimi, ticari açıklık ve çevre koruma harcamaları kullanılmıştır. Yapılan analiz sonucunda Türkiye'nin bölgelerinde 2007-2019 dönemi için ÇKE hipotezinin geçerli olmadığı bulgusuna ulaşılmıştır. Bunun yanında çalışmada enerji tüketiminin çevre kirliliğini istatistiksel olarak anlamlı ve pozitif, ticari açıklığın ise negatif etkilediği tespit edilmiştir. Ancak çevre koruma harcamalarının her iki modelde de çevre kirliliği üzerinde istatistiksel açıdan anlamlı etkileri yakalanamamıştır. Bu sonuç çevresel tahribatı azaltmak için yapılan çevre koruma harcamalarının etkin olmadığını ortaya koymuştur.

Sürdürülebilir ekonomik kalkınmanın sağlanması için sürdürülebilir bir çevre politikasına sahip olunması gerekmektedir. Bu bağlamda ülkelerin çevre kirliliğini azaltacak politikaları uygulamasında büyük yarar bulunmaktadır. Özellikle enerji tüketimi içerisindeki fosil yakıt tüketiminin azaltılması, ikili ticari ilişkileri 
gerçekleştirirken çevreyi daha az kirletecek sektörlere ağırlık verilmesi ve çevresel kalite üzerinde etkili olan mali politikaların hayata geçirilmesi gerekmektedir. Öte yandan bu çalışmada bölgesel veri kısıtı nedeniyle ÇKE hipotezi kısa bir dönem için test edilebilmiştir. Kapsamlı ampirik araştırmalar için yeterli bir veri setine sahip olunduğunda hem dönemsel farklılıkları inceleyen hem de bölgesel farklılıkları ortaya koyan ve bu doğrultuda ÇKE hipotezini test eden çalışmalar yapılabilir.

\section{Kaynakça}

Acaravci, A., \& Ozturk, I. (2010). "On the Relationship between Energy Consumption, CO2 Emissions and Economic Growth in Europe", Energy, 35(12), 5412-5420.

Akbostancı, E., Türüt-Aşık, S., \& Tunç, G. ì. (2009). "The Relationship between Income and Environment in Turkey: Is there an Environmental Kuznets curve?", Energy Policy, 37(3), 861-867.

Akyıldız, B. (2008). "Çevresel Etkinlik Analizi: Kuznets Eğrisi Yaklaşımı”, Yüksek Lisans Tezi, Dokuz Eylül Üniversitesi Sosyal Bilimler Enstitüsü, İzmir.

Apergis, N., \& Ozturk, I. (2015). "Testing Environmental Kuznets Curve Hypothesis in Asian Countries", Ecological Indicators, 52, 16-22.

Arellano, M., \& Bond, S. (1991). "Some Tests of Specification for Panel Data: Monte Carlo Evidence and an Application to Employment Equations", The Review of Economic Studies, 58(2), 277-297.

Arellano, M., \& Bover, O. (1995). "Another Look at the Instrumental Variable Estimation of Error-Components Models", Journal of Econometrics, 68(1), 2951.

Arouri, M. E. H., Youssef, A. B., M'henni, H., \& Rault, C. (2012). “Energy Consumption, Economic Growth and $\mathrm{CO} 2$ Emissions in Middle East and North African Countries", Energy Policy, 45, 342-349.

Artan, S., Hayaloğlu, P., \& Seyhan, B. (2015). "Türkiye'de Çevre Kirliliği, Dışa Açıklık ve Ekonomik Büyüme Ilişsisi", Yönetim ve Ekonomi Araştırmaları Dergisi, 13(1), 308-325.

Atıcı, C., \& Kurt, F. (2007). “Türkiye'nin Dış Ticareti ve Çevre Kirliliği: Çevresel Kuznets Eğrisi Yaklaşımı", Tarım Ekonomisi Dergisi, 13 (2), 61-69.

Ayyıldız, B., \& Gürler, A. Z. (2017). "Yeşilırmak Tarım Havzası'nda Yer Alan İllerin Çevresel Kirlenmede Etkili Olan Parametrelere Göre Çke Eğrisi ille Analizi", Gaziosmanpaşa Bilimsel Araştırma Dergisi, 6,Özel Sayı, 110-117. 
Balado-Naves, R., Baños-Pino, J. F., \& Mayor, M. (2018). "Do Countries Influence Neighbouring Pollution? A Spatial Analysis of the EKC for CO2 Emissions". Energy Policy, 123, 266-279.

Balıbey, M. (2015). "Relationships among CO2 Emissions, Economic Growth and Foreign Direct Investment and the Environmental Kuznets Curve Hypothesis in Turkey", International Journal of Energy Economics and Policy, 5(4), 1042-1049.

Başar, S., \& Temurlenk, M. S. (2007). “Çevreye Uyarlanmış Kuznets Eğrisi: Türkiye Üzerine Bir Uygulama", Atatürk Üniversitesi Iktisadi ve Idari Bilimler Dergisi, 21(1), 1-12.

Bento, J. P. C., \& Moutinho, V. (2016). “CO2 Emissions, Non-Renewable and Renewable Electricity Production, Economic Growth, and International Trade in Italy", Renewable and Sustainable Energy Reviews, 55, 142-155.

Blundell, R., \& Bond, S. (1998). "Initial Conditions and Moment Restrictions in Dynamic Panel Data Models", Journal of Econometrics, 87(1), 115-143.

Bostan, I., Onofrei, M., Dascălu, E. D., Fîrțescu, B., \& Toderașcu, C. (2016). "Impact of Sustainable Environmental Expenditures Policy on Air Pollution Reduction, During European Integration Framework", Amfiteatru Economic Journal, 18(42), 286-302.

Cheikh, N. B., Zaied, Y. B., \& Chevallier, J. (2021). "On the Nonlinear Relationship between Energy Use and CO2 Emissions within an EKC Framework: Evidence from Panel Smooth Transition Regression in the MENA Region", Research in International Business and Finance, 55, 101331.

Choi, E., Heshmati, A., \& Cho, Y. (2010). "An Empirical Study of the Relationships between CO2 Emissions, Economic Growth and Openness", IZA Discussion Paper, No. 5304.

Çağlar, A. E., \&, Mert, M. (2017). “Türkiye'de Çevresel Kuznets Hipotezi ve Yenilenebilir Enerji Tüketiminin Karbon Salımı Üzerine Etkisi: Yapısal Kırılmalı Eşbütünleşme Yaklaşımı", Yönetim ve Ekonomi, 24(1), 21-38.

Çatık, A. N., Karaçuka, M., \& Kışla, G. H. (2016). "Air Pollution and Income Relationship in Turkish Provinces: A Spatial Approach", Marmara Üniversitesi iktisadi ve Idari Bilimler Dergisi, 38(1), 127-146.

Çevre ve Şehircilik Bakanlığı (2020). Çevresel Göstergeler, Çevresel Etki Değerlendirmesi, İzin ve Denetim Genel Müdürlüğü, Ankara.

Çil Yavuz, N. (2014). "CO2 Emission, Energy Consumption, and Economic Growth for Turkey: Evidence from a Cointegration Test with a Structural Break", Energy Sources, Part B, 9, 229-235.

Dam, M. M., Karakaya, E., \& Bulut Ş. (2013). “Çevresel Kuznets Eğrisi ve Türkiye: Ampirik Bir Analiz", Dumlupınar Üniversitesi Sosyal Bilimler Dergisi, EYi 2013 Özel Sayısı, 85-96. 
Deveci, A. \& Sakallı, A. (2019). “Çevre Kirliliği ve Ekonomik Büyüme Arasındaki İlişkinin 1990-2018 Yılları Arasında Hatay için İncelenmesi", Akademik Sosyal Araştırmalar Dergisi, 6(37), 427-440.

Dinda, S. (2004). "Environmental Kuznets Curve Hypothesis: A Survey", Ecological Economics, 49(4), 431-455.

Ercolano, S., \& Romano, O. (2017). "Spending for the Environment: General Government Expenditure Trends in Europe", Social Indicators Research, 138(3), 1145-1169.

Erdoğan, ì., Türköz, K., \& Görüş, M. Ş. (2015). "Çevresel Kuznets Eğrisi Hipotezinin Türkiye Ekonomisi için Geçerliliği", Dumlupınar Üniversitesi Sosyal Bilimler Dergisi, 44, 113-123.

Fukase, E. (2010). "Revisiting Linkages between Openness, Education and Economic Growth: System GMM Approach", Journal of Economic Integration, 193-222.

Gholipour, H. F., \& Farzanegan, M. R. (2018). "Institutions and the Effectiveness of Expenditures on Environmental Protection: Evidence from Middle Eastern Countries", Constitutional Political Economy, 29(1), 20-39.

Gozgor, G. \& Can, M. (2016). "Export Product Diversification and the Environmental Kuznets Curve: Evidence from Turkey", Environmental Science and Pollution Research, 23(21), 21594-21603.

Grossman, G. M. \& Krueger, A. B. (1991), "Environmental Impacts of a North American Free Trade Agreement", National Bureau of Economic Research, No: 3914.

Güçlü, M. (2016). "The Environmental Kuznets Curve for Turkish Nuts-3 Regions: A Spatial Econometric Analysis", 12. ASECU Conference-Inclusive and Sustainable Development and the Role of Social and Solidarity Economy, 29-30 Eylül 2016, Eskişehir.

Güney, A. (2018). “Genişletilmiş Çevresel Kuznets Eğrisinin Türkiye İçin Yeniden Değerlendirilmesi", Atatürk Üniversitesi iktisadi ve Idari Bilimler Dergisi, 32(3), 745-761.

Güriş, S., \& Şak, N. (2019). "Çevresel Kuznets Eğrisi Hipotezinin Toplamsal Olmayan Sabit Etkili Panel Kantil Yöntemiyle İncelenmesi", Business and Economics Research Journal, 10(2), 327-340.

Halicioglu, F. (2009). “An Econometric Study of CO2 Emissions, Energy Consumption, Income and Foreign Trade in Turkey", Energy Policy, 37, 1156-1164.

He, L., Wu, M., Wang, D., \& Zhong, Z. (2018). "A Study of the Influence of Regional Environmental Expenditure on Air Quality in China: The Effectiveness of Environmental Policy", Environmental Science and Pollution Research, 25(8), 7454-7468. 
Heidari, H., Katircioğlu, S. T., \& Saeidpour, L. (2015). "Economic Growth, CO2 Emissions, and Energy Consumption in the Five ASEAN Countries", International Journal of Electrical Power \& Energy Systems, 64, 785-791.

Huang, J. T. (2018). "Sulfur Dioxide (SO2) Emissions and Government Spending on Environmental Protection in China-Evidence from Spatial Econometric Analysis", Journal of Cleaner Production, 175, 431-441.

Jebli, M. B., Youssef, S. B., \& Ozturk, I. (2016). “Testing Environmental Kuznets Curve Hypothesis: The Role of Renewable and Non-Renewable Energy Consumption and Trade in OECD Countries", Ecological Indicators, 60, 824-831.

Kamal, M., Usman, M., Jahanger, A. \& Balsalobre-Lorente, D. (2021). "Revisiting the Role of Fiscal Policy, Financial Development, and Foreign Direct Investment in Reducing Environmental Pollution during Globalization Mode: Evidence from Linear and Nonlinear Panel Data Approaches", Energies 2021, 14, 6968.

Karaçayır, E. \& Güney, T. (2016). “Çevresel Kuznets Eğrisi Hipotezinin Geçerliliği: KOP Bölgesi Üzerine Bir Uygulama”, 4. International Symposium on Development of KOP Region, 21-23 Ekim 2016, Karaman.

Kasman, A., \& Duman, Y. S. (2015). "CO2 Emissions, Economic Growth, Energy Consumption, Trade and Urbanization in New EU Member and Candidate Countries: A Panel Data Analysis", Economic Modelling, 44, 97-103.

Katircioglu, S. T. \& Taşpinar, N. (2017). "Testing the Moderating Role of Financial Development in an Environmental Kuznets Curve: Empirical Evidence from Turkey", Renewable and Sustainable Energy Reviews, 68(1), 572-586.

Keyifli, N., \& Akdede, S. H. (2017). "Devletin Hacmini Belirleyen Faktörler: Ampirik Bir Analiz", International Journal of Public Finance, 2(1), 81-92.

Kılıç, R. \& Akalın, G. (2016). “Türkiye'de Çevre ve Ekonomik Büyüme Arasındaki İlişki: ARDL Sınır Testi Yaklaşımı”, Anadolu Üniversitesi Sosyal Bilimler Dergisi, 16(2), 49-60.

Kocak, E. (2014). “Türkiye'de Çevresel Kuznets Eğrisi Hipotezinin Geçerliliği: ARDL Sınır Testi Yaklaşımı", Iş̧letme ve iktisat Çalışmaları Dergisi, 2(3), 62-73.

Kuznets, S. (1955). "Economic Growth and Income Inequality", The American Economic Review, 45(1), 1-28.

Le, H. P., \& Ozturk, I. (2020). “The Impacts of Globalization, Financial Development, Government Expenditures, and Institutional Quality on CO2 Emissions in the Presence of Environmental Kuznets Curve", Environmental Science and Pollution Research, 27(18), 22680-22697.

Lebe, F. (2016). "Çevresel Kuznets Eğrisi Hipotezi: Türkiye için Eşbütünleşme ve Nedensellik Analizi", Doğuş Üniversitesi Dergisi, 17 (2), 177-194. 
Lopez, R., Galinato, G. I., \& Islam, A. (2011). "Fiscal Spending and the Environment: Theory and Empirics", Journal of Environmental Economics and Management, $62,180-198$.

Moshiri, S., \& Daneshmand, A. (2020). "How Effective is Government Spending on Environmental Protection in a Developing Country? An Empirical Evidence from Iran", Journal of Economic Studies, 47(4), 789-803.

Mutlu, A. (2006). “Küresel Kamusal Mallar Bağlamında Sağlık Hizmetleri ve Çevre Kirlenmesi: Üretim, Finansman ve Yönetim Sorunları", Maliye Dergisi, 150, 5378.

Ozatac, N., Gokmenoglu, K. K., \& Taspinar, N. (2017). "Testing the EKC Hypothesis by Considering Trade Openness, Urbanization, and Financial Development: The Case of Turkey", Environmental Science and Pollution Research, 24(20), 1669016701.

Pao, H. T., \& Tsai, C. M. (2010). "CO2 Emissions, Energy Consumption and Economic Growth in BRIC Countries", Energy Policy, 38(12), 7850-7860.

Pata, U. K. (2019). "Environmental Kuznets Curve and Trade Openness in Turkey: Bootstrap ARDL Approach with a Structural Break", Environmental Science and Pollution Research, 26(20), 20264-20276.

Pata, U. K., \& Caglar, A. E. (2021). "Investigating the EKC Hypothesis with Renewable Energy Consumption, Human Capital, Globalization and Trade Openness for China: Evidence from Augmented ARDL Approach with a Structural Break", Energy, 216, 119220.

Saatçi, M., \& Dumrul, Y. (2011). “Çevre kirliliği ve Ekonomik Büyüme illişkisi: Çevresel Kuznets Eğrisinin Türk Ekonomisi için Yapısal Kırılmalı Eş-bütünleşme Yöntemiyle Tahmini", Erciyes Üniversitesi iktisadi ve Idari Bilimler Fakültesi Dergisi, (37), 65-86.

Shahbaz, M., Solarin, S. A., Hammoudeh, S., \& Shahzad, S. J. H. (2017). “Bounds Testing Approach to Analyzing the Environment Kuznets Curve Hypothesis with Structural Beraks: The Role of Biomass Energy Consumption in the United States", Energy Economics, 68, 548-565.

Sharma, S. S. (2011). "Determinants of Carbon Dioxide Emissions: Empirical Evidence from 69 Countries", Applied Energy, 88(1), 376-382.

Sinha, A., \& Shahbaz, M. (2018). "Estimation of Environmental Kuznets Curve for CO2 Emission: Role of Renewable Energy Generation in India", Renewable Energy, 119, 703-711.

Sinha, A., Shahbaz, M., \& Balsalobre, D. (2017). "Exploring the Relationship between Energy Usage Segregation and Environmental Degradation in N-11 Countries", Journal of Cleaner Production, 168, 1217-1229. 
Stern, D. I. (2004). "The Rise and Fall of the Environmental Kuznets Curve", World Development, 32(8), 1419-1439.

Şahin, G. (2018). “Çevresel Sürdürülebirlik Kapsamında Türkiye Düzey-2 Alt Bölgeleri Üzerine Bir Çözümleme”, Doktora Tezi, İnönü Üniversitesi Sosyal Bilimler Enstitüsü, Malatya.

Tuzcu, S. E., \& Usupbeyli, A. (2018). “Çevresel Kuznets Eğrisi: Türkiye Üzerine Gece Işıkları ile Mekânsal bir Modelleme", Çankırı Karatekin Üniversitesi Iktisadi ve Idari Bilimler Fakültesi Dergisi, 8(1), 141-164.

Yavan, S., \& Hotunluoğlu, H. (2018). "Yerel Yönetimlerin Çevre Harcamaları İle Hava Kalitesi İlişkisi: il Bazlı Bir Analiz”, Aydın iktisat Fakültesi Dergisi, 3(1), 36-47.

Yerdelen Tatoğlu, F. (2013). Ileri Panel Veri Analizi: Stata Uygulamalı, 2. Baskı, Beta Yayınları, İstanbul.

Zafar, M. W., Mirza, F. M., Zaidi, S. A. H., \& Hou, F. (2019). "The Nexus of Renewable and Nonrenewable Energy Consumption, Trade Openness, and CO2 Emissions in the Framework of EKC: Evidence from Emerging Economies", Environmental Science and Pollution Research, 26(15), 15162-15173. 